\title{
Ancient Greek Illustrated Dioscoridean Herbals: Origins and Impact of the Juliana Anicia Codex and the Codex Neopolitanus
}

\author{
Jules JANICK ${ }^{1}$, John STOLARCZYK² \\ ${ }^{1}$ Purdue University, Department of Horticulture and Landscape Architecture, West Lafayette, IN 47907, USA; janick@purdue.edu \\ ${ }^{2}$ World Carrot Museum, 51 Clayton Hall Road, Cross Hills, Skipton UK
}

\begin{abstract}

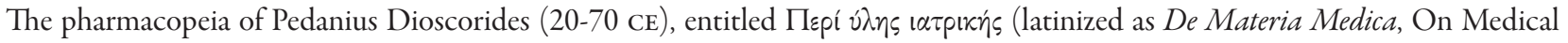
Matters) was written in Greek about the year 65. It was destined to be one of the most famous books on pharmacology and medicine but is also rich in horticulture and plant ecology. An illustrated alphabetical version of Dioscorides' manuscript was completed in Constantinople about 512. This magnificent volume was prepared and presented to the imperial Princess Juliana Anicia (462-527), daughter of the Emperor Anicius Olybrius, Emperor of the Western Roman Empire. The bound manuscript stored in Ōsterreichische Nationalbibliothek in Vienna is available in facsimile and is now referred to as the Juliana Anicia Codex (JAC) or the Codex Vindobonensis Dioscorides. The $J A C$ contains 383 paintings of plants including many horticultural crops, many of which can still be recognized in modern day examples. An analysis of the illustrations indicates that they were made by numerous artists of varying skills and it is probable that some were derived from an earlier lost version. The Codex Neapolitanus (NAP) (late $6^{\text {th }}$ or early $7^{\text {th }}$ century) which now contains 406 plant images on 172 folios resides in the Biblioteca Nazionale, Naples is closely related to $J A C$, and is also available in facsimile editions. A comparison of the 352 common illustrations contained in both $N A P$ and $J A C$ suggests that many of the illustrations derived from a common source, perhaps an illustrated collection owned by Theodosius II, but the possibility also exists that some of the NAP images are direct copies of $J A C$ images. There are 31 images in $J A C$ which do not appear in $N A P, 1$ is a $13^{\text {th }}$ century addition, 4 are images that can be assigned to 2 torn pages. and 26 can be assigned to 11 missing leaves of the NAP. Of the 54 images in $N A P$ which do not appear in $J A C$, 2 are likely to have been Mandragora included in lost folios in $J A C$, but the other 52 may include other images that existed in the common source. While common images in $N A P$ and $J A C$ are often very similar, $11.6 \%$ show substantially differences including variants of the same plant in different stages. Additional images in the archetypic source including different stages of the same plant could have provided the copyists working on $J A C$ and $N A P$ the opportunity to select different images to fulfill their commissions.
\end{abstract}

Keywords: Dioscorides, Greek herbals, Juliana Anicia, plant illustration

\section{Introduction}

The Greek pharmacopeia of Pedanios Dioskurides (latinized as Pedanius Dioscorides, 20-70 CE) entitled Пвpi

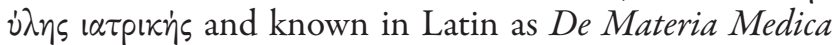
(On Medical Matters) was written about the year 65. Dioscorides hailed from Anazarbus, a small city northeast of Tarsus in the Roman Province of Cilicia (now Turkey), and possibly served as a medical officer in the Roman legions. The treatise consisting largely of descriptions of plants stressing their medicinal uses has been considered one of the most famous works in pharmacology despite its non-scientific approach (Singer, 1927; Scarborough and Nutten, 1982; Collins, 2000). The original non-illustrated manuscript no longer extant, contained medical information on about 600 plants, 35 animal products, and 90 minerals. The work was divided into five books based on drug affinity: (1) Aromatic Oils Ointments, Trees; (2) Living Creatures, Milk and Dairy Products, Cereals and Sharp Herbs; (3) Roots, Juices Herbs; (4) Herbs and Roots; and (5) Vines and Wines, Metallic Ores. Max Wellmann (1906-1914) published a critical Greek edition in 3 volumes in 1906-1914. This version has been translated from Greek into English by Lily Beck (2005).

Dioscorides, in a preface acknowledging his teacher Areios, criticizes his predecessors for their organization of herbs, inaccurate procedures, and erroneous content. (Scarborough, 1982). He added details from personal experience based on his broad travels. He also included information that he learned from oral tradition and from previous texts. Included was a study of the 130 plants of the Hippocratic Collection and more than 11 plants from Crataeus, Greek physician to Mithridates VI Emperor, King of Pontus, and author of a lost herbal, Agrimonia eupatorium. Subsequent revisions and recensions, some ordered alphabetically, added illustrations. Two famous illustrated Greek recensions reorganized the information alphabetically: the Juliana Anicia Codex $(J A C)$ completed in 512 and the Codex Neapolitanus (NAP) considered to be late $6^{\text {th }}$ or early $7^{\text {th }}$ century. Throughout the centuries 
10

$P Y I$, was also translated into Arabic, Persian, Latin and other languages, and the $J A C$ became the model for most herbals of the West. For example, the Latin herbal of Pier Andrea Mattioli (1544), was entitled Commentary on the Six [sic] Books of Dioscorides. The objective of this paper is to explore the relationship between $J A C$ and $N A P$ based on an analysis of the illustrations they contain. The association of the illustrations and the Greek text is discussed by Collins (2000) and will not be treated here.

\section{Juliana Anicia Codex}

The oldest surviving and most famous recension of $P Y I$, was prepared and presented to the imperial Princess Juliana Anicia (462-527), daughter of Anicius Olybrius, Emperor of the Western Roman Empire. The bound volume, the most prized possession of the Österreichische Nationalbibliothek in Vienna, Austria, is available in facsimile and is now referred to either as the Juliana Anicia Codex $(J A C)$ or the Codex Vindobonensis. This volume celebrates its sesquimillennial anniversary in 2012. The $J A C$ is a magnificent, gloriously illustrated Byzantine version of PYI, completed in Constantinople about 512, reformatted in an alphabetical arrangement by initial letter that also includes sections on fishing and bird catching. It contains 383 paintings of Mediterranean plants many of which can still be recognized in modern day examples (Janick and Hummer, 2012). Analysis of the illustrations indicates that they were made by numerous artists of varying skills. Some images were probably derived from earlier PYI versions now lost to history. The frontis section of the manuscript contains a portrait of Princess Juliana honored as a religious devotee and patron of the arts of the town of Honorata (Fig. 1). This is the earliest donor portrait in an extant manuscript illumination. There are also two paintings of Dioscorides (Fig. 2) and portraits of then famous physicians and philosophers. The tome is accessible in a two volume German facsimile edition, Der Wiener Dioskurides (1998, 1999). No complete English translation of the $J A C$ exists.

The provenance of the $J A C$ has been examined by Singer (1927), Heyd (1963), Blunt and Raphael (1994), and Collins (2000). It was fully restored and rebound in 1406 by the notary John Chortasmenos at the request of Nathaniel, a monk at the St. John Prodromos Monastery in Constantinople, who placed the cursive numberings on

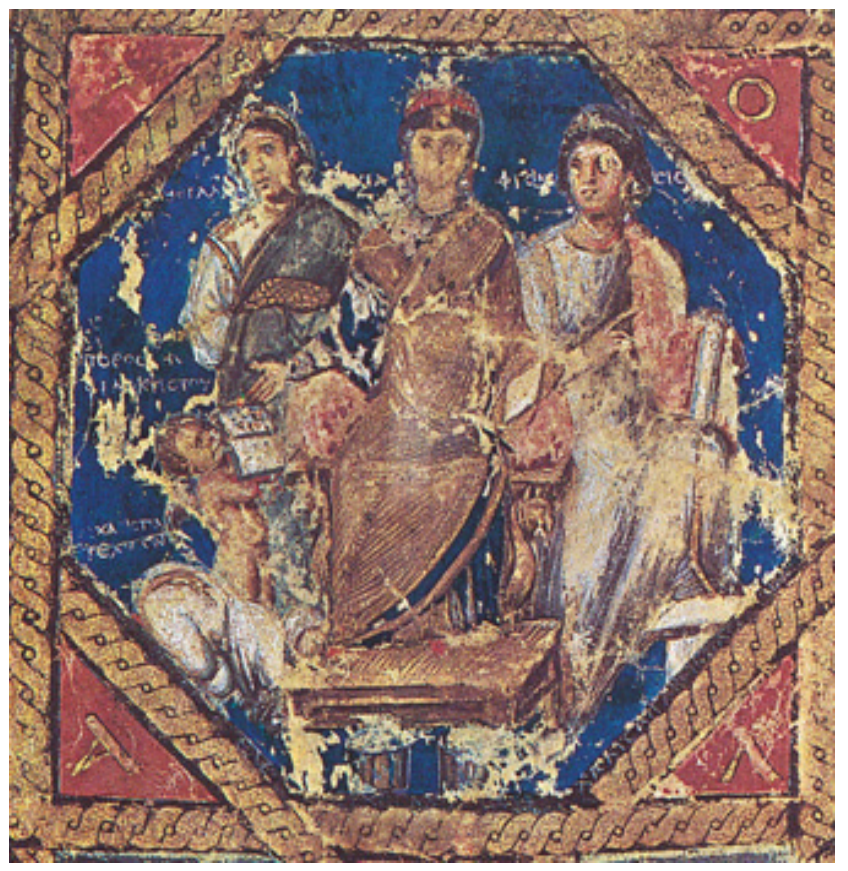

Fig. 1. Dedicatory drawing of Imperial Princess Julian Anicia (center) in the Dioscoridean recension of $512 \mathrm{CE}(J A C)$, flanked by personification of Magnanimity on her right who holds gold coins and Wisdom on her left with scroll or codex. The Cupidlike putto offers an open codex and a prostrate female represents craftsmen who restored the church in Honorata on the beneficence of the princess


Fig. 2. Image in $J A C$ of artist painting a mandrake held by Epinoia, incarnation of thought and intelligence, while Dioscorides is absorbed with his book. Sketch on right by M. Breen (D’Andrea, 1982) 
the plant paintings and the transcript of the plant titles and some descriptions in Greek minuscule. Subsequent owners added Arabic, Greek, and Hebrew plant names alongside the illustrations. The manuscript eventually became part of the private collection of the Moses Hamon (ca. 14901554), a Jewish physician and favorite of the Ottoman Sultan, Suleman the Magnificent, and was seen by Ogier Ghiselin de Busbecq (1522-1592), Flemish writer, herbalist, and diplomat who served as ambassador to the Ottoman Empire in Istanbul. Busbecq was a collector of coins, manuscripts, curios, and plant materials but was deterred from purchasing it by the price (100 ducats), and pressed the Emperor Ferdinand I to purchase it. The manuscript was finally purchased by Ferdinand's son Maximillian II, and it arrived in Vienna about 1569 and was deposited in the Imperial Library in Vienna in 1592.

\section{Codex Neapolitanus}

The illustrated Codex Neapolitanus dates to the late $6^{\text {th }}$ or early $7^{\text {th }}$ century and since 1923 resides in the Biblioteca Nazionale, Naples (Blunt and Raphael, 1979; Orofino, 1992; Collins, 2000). A facsimile was produced in 1988 (Codex Neapolitanus Graecus of the National Agricultural Library of Naples) with various commentaries. Although $N A P$ contains more plant images than the opulent $J A C$, it is physically much smaller. This was accomplished by formatting most pages with multiple images, side by side (2 to 4 ) on a page and reducing the text. Some of the images are compressed to fit the page and as a result appear somewhat distorted.

The origin of the NAP is obscure (Collins, 2000). Although it could have been produced in Constantinople there is conjecture that it was produced in Rome, instigated by Cassiodorus (ca. 485-585), Roman statesman, writer, and senator, during his sojourn in Constantinople. The absence of Arabic or Hebrew annotations and the presence of transcriptions of Greek names to Latin synonyms by different hands in the $13^{\text {th }}$ and $14^{\text {th }}$ centuries indicate its provenance in southern Italy. It became part of the collec- tion of the library of the monastery of San Giovanni Carbonara in Naples in 1531. In 1716 the Codex was taken to Vienna by the Emperor Charles VI but it was reclaimed by the Italians and was consigned to the Biblioteca Nazionale in Naples in 1923.

\section{Plant Illustrations of the $J A C$ and $N A P$}

Both herbals written in Greek are based on a first letter alphabetical arrangement of the titles of the plant images. The order of the folios of NAP were disturbed sometime between the $11^{\text {th }}$ and $15^{\text {th }}$ centuries when the Codex was rebound (Cavallo, 2000) but the alphabetical arrangement makes it possible to reconstruct the original sequence. In this paper the Latin binomials for the plants are based on the designations of Otto Mazal, the editor of the $J A C$ facsimile although they are not always definitive (Janick and Hummer, 2012). JAC includes 383 plant images on 377 folios: 371 are presented individually on a single folio leaf and 6 folios have two images per leaf (Tab. 1). NAP includes 406 images on 172 folios all on the right hand side: 2 folios have a single image, 103 contain 2 images, 62 contain 3 images, and 3 contain 4 images. Two damaged torn pages that, based on the captions, once contained two images each contain 0 images.

Tab. 1. Relationship between illustrations of $J A C$ and $N A P$

\begin{tabular}{|c|c|c|c|c|c|c|c|}
\hline \multirow[b]{2}{*}{ Codex } & \multirow{2}{*}{$\begin{array}{l}\text { Total } \\
\text { images }\end{array}$} & \multicolumn{4}{|c|}{ No. images } & \multirow{2}{*}{$\begin{array}{c}\text { No. } \\
\text { common } \\
\text { images }\end{array}$} & \multirow{2}{*}{$\begin{array}{c}\text { No. } \\
\text { unique } \\
\text { images }\end{array}$} \\
\hline & & $\begin{array}{c}1 / \\
\text { page }\end{array}$ & $\begin{array}{c}2 / \\
\text { page }\end{array}$ & $\begin{array}{c}3 / \\
\text { page }\end{array}$ & $\begin{array}{c}\text { 4/ } \\
\text { page }\end{array}$ & & \\
\hline NAP & 406 & 2 & 206 & 186 & 12 & 352 & 54 \\
\hline$J A C$ & 383 & 371 & 12 & -- & -- & 352 & 31 \\
\hline
\end{tabular}

There are 352 images common to both herbals. In addition, there are 54 unique images in NAP and 31 in JAC.

At least two of the 54 unique images in $N A P$ are due to a missing folio of $J A C$. Pages 287-289 in JAC are in a different script and include a rough sketch of anthropomorphized mandrake (Fig. 3) which is identified as a $13^{\text {th }}$

\section{XC right}
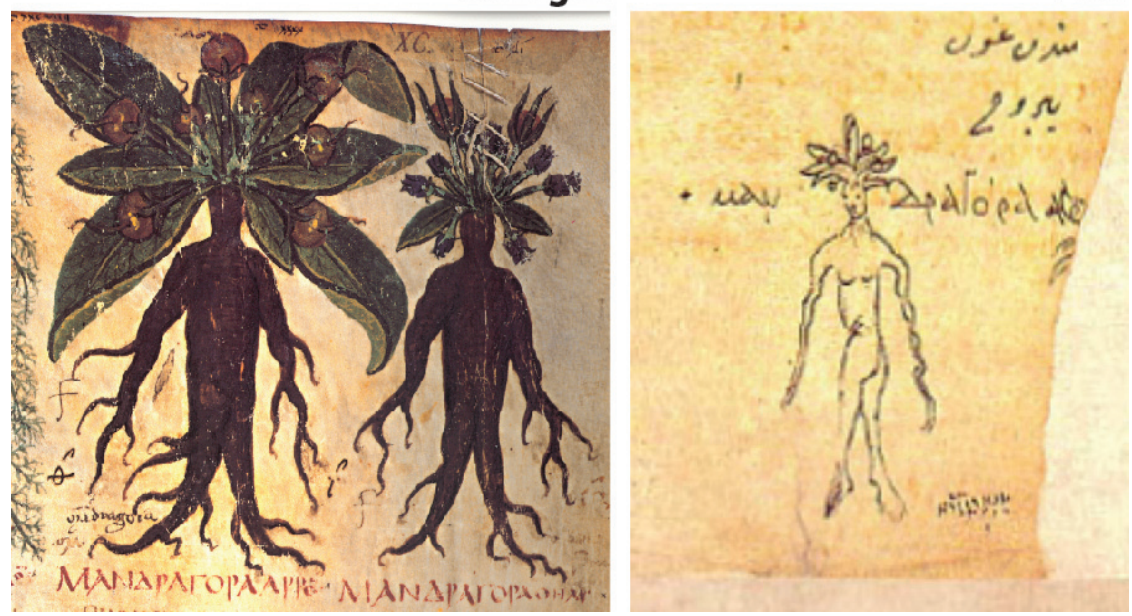

Fig. 3. Two figures of mandrake from $N A P$ (left) compared to the sketch of mandrake in $J A C$ (right) which is a $13^{\text {th }}$ or $14^{\text {th }}$ century interpolation 
12

or $14^{\text {th }}$ century addition (Scarborough, pers. commun.). Clearly the original folio of Mandragora is lost since images occur in prefatory illustrations (see Fig. 2). We assume therefore that the two forms of mandrake in $N A P$ must have been included in $J A C$. The remaining 52 unique $N A P$ images suggest that there were additional images other than those in $J A C$ available to the $N A P$ copyists. We conclude that $N A P$ is an extended version of $J A C$.

Of the 31 unique images in $J A C$, one (Spartium junceum) is a $13^{\text {th }}$ century addition according to Otto Mazal, four can be accounted for in NAP by two torn pages ( $\mathrm{p}$. 122 and 161), and 26 can be accounted for by missing pages. The two images missing from p. 122 are Euphorbia pepius and Marrubium vulgare while the two images from p. 161 are Sium latifolium and Apium graveolens. At least 11 leaves have been identified as missing from NAP (Cavallo, 2000) which based on its configuration of two to four images per leaf accounts for the remaining 26 "unique" images of $J A C$. Of these 26 unique images, 17 begin with the Greek letter " $A$ " and there are 6 missing pages at the beginning of the volume (Cavallo, 2000). However, one unique image of Aegilops 128r is almost identical to 56v. Furthermore the unique image $97 \mathrm{r}$ identified as Bryonia celtica is close to $82 \mathrm{r}(\mathrm{B}$. alba). This latter image has been identified as Humulus lupulus (Renner et al., 2008).

\section{Comparisons of Common Images}

The 352 common images were scored by the authors independently for similarity on a scale of 1 (almost identical) to 5 (completely different) with $83 \%$ congruence. Where there were differences in scoring the higher value was used. Because the color of the NAP drawings seem to have faded or blackened due to pigment deterioration over time, only extreme color differences were considered. Of the 352 common images, 311 were rated either 1 or 2 , almost identical or only slightly different $(88.4 \%)$; 38 were rated 3 or 4 , substantial or large differences $(10.8 \%)$, and 3 were rated 5 , different ( $0.8 \%)$ (Tab. 2). In general the $N A P$ drawings were considered to be cruder than those in $J A C$

Tab. 2. Variation scores comparing common images of $N A P$ and $J A C$

\begin{tabular}{lcc}
\hline \multicolumn{1}{c}{ Rating } & No. images & Percent \\
\hline 1 (almost identical) & 231 & 65.7 \\
2 (slight difference) & 80 & 22.7 \\
3 (substantial difference) & 28 & 8.0 \\
4 (large difference) & 10 & 2.8 \\
5 (different) & 3 & 0.8 \\
Total & 352 & 100.0 \\
\hline
\end{tabular}

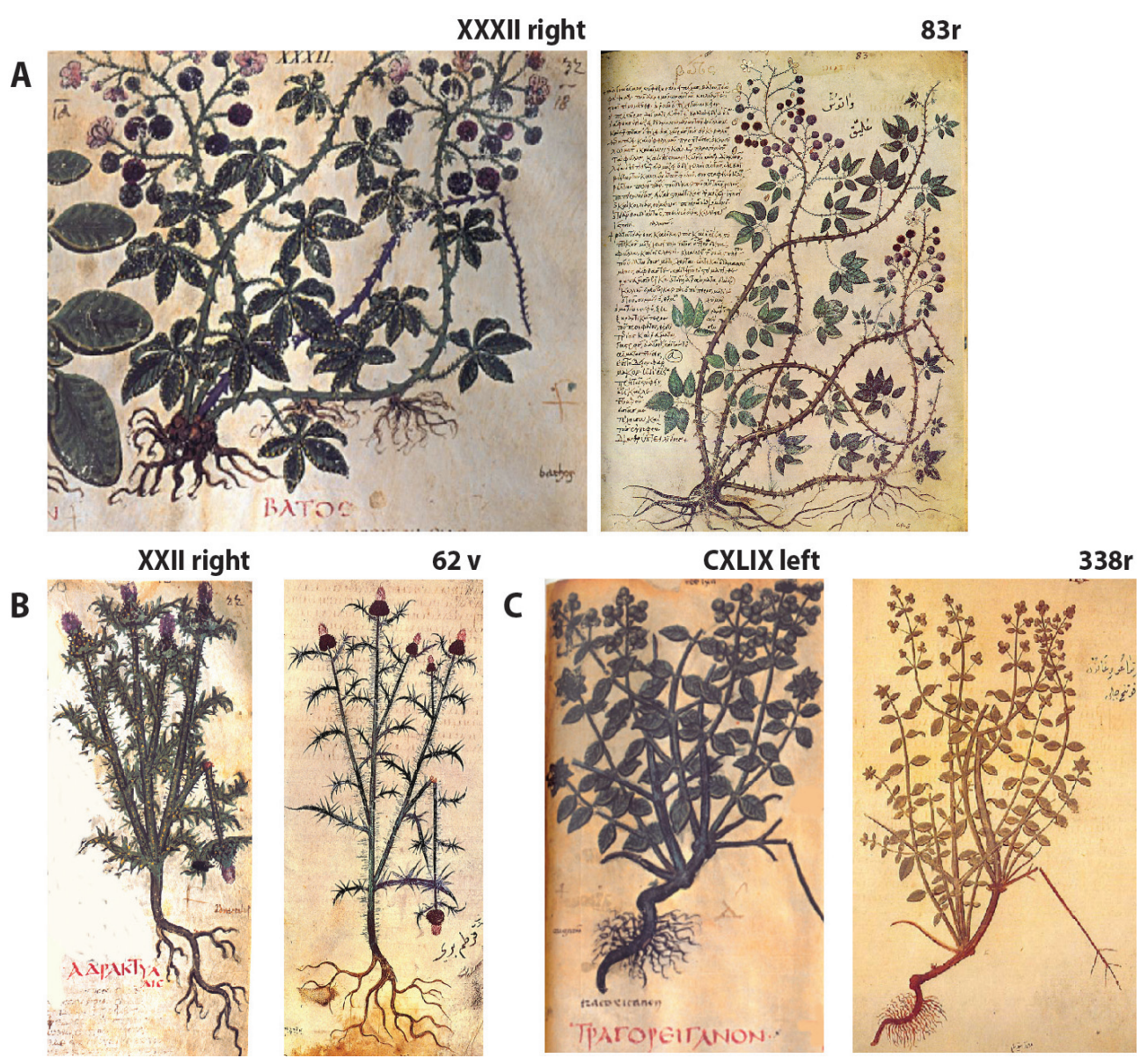

Fig. 4. Broken stems in images of NAP (left) and JAC (right): (A) Rubus tomentosa, (B) Carthamus lanatus, and (C) Thymus graveolens 

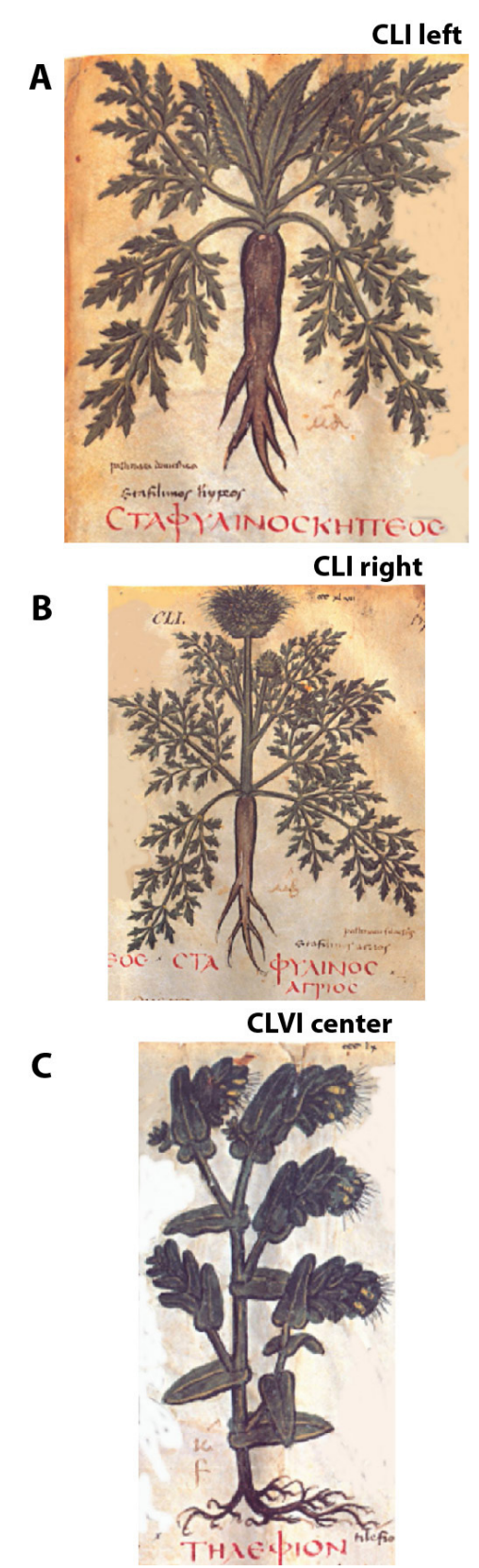

Fig. 5. Similar images in $N A P$ (left) and JAC (right): (A) Daucus carota, (B) D. silvestris, (C) Cerinthe aspera

but in some cases botanically more precise as in the case of leaves and petals in Rubus tomentosa and pod morphology in Vicia faba.

Some of the images in NAP are uncannily similar to $J A C$ and include identical minute details such as a broken stem in exactly the same place and at the same angle (Fig. 4), the overall shape and plant configuration (Fig. 5), and cases of plants emerging from a crude container or matrix (Fig. 6). These similarities in $J A C$ and $N A P$ indicate that $N A P$ was either copied directly from $J A C$ or copied from the same archetype version.

The variations in some images involved flower color and morphology, leaf form, number of branches and branching pattern, and stage difference such as flower-

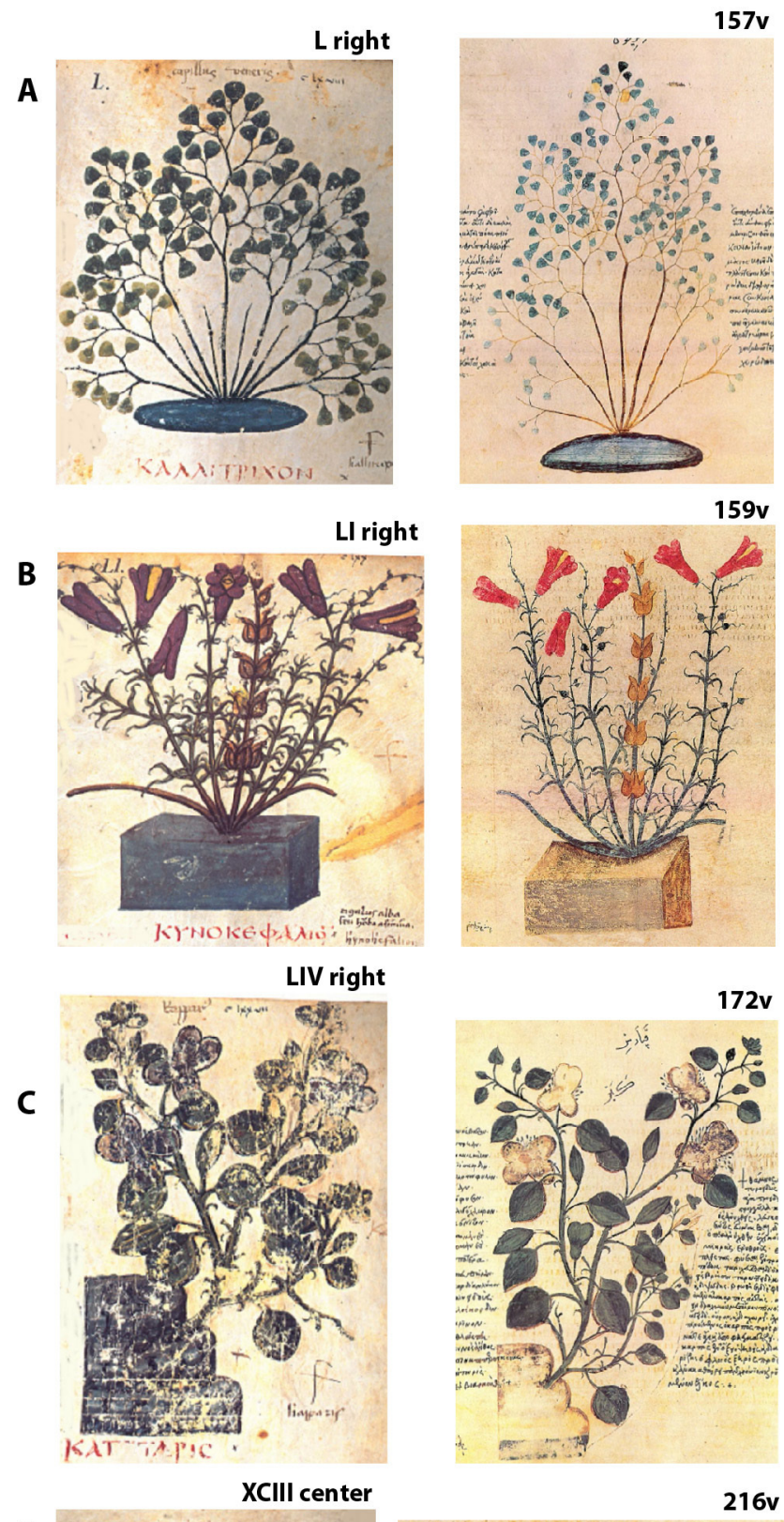

D
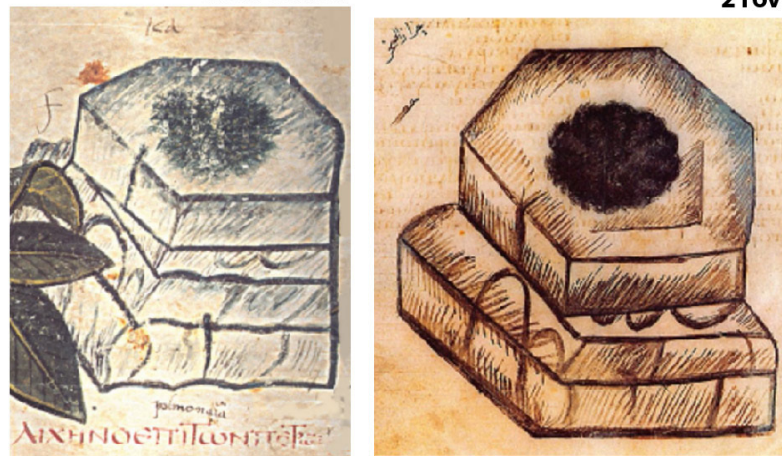

Fig. 6. Similar crude container or matrix in $N A P$ (left) and $J A C$ (right): (A) Adiantum capillus veneris, (B) Antirrbinum majus, (C) Capparris spinosa, (D) Peltigera canina

ing versus non-flowering, and inflorescences stage. These differences are suggestive of different source images being copied rather than copyist changes. There were 41 variant 
14

comparisons (rated 3-5) between NAP and JAC: 14 stage differences, 3 branching, 9 size, 2 leaves, 11 flowers, and 2 totally different. Examples of stage differences are shown in Fig. 7.

Illustrations common to $N A P$ and $J A C$ can also be shown to have artistic differences, which would be a reflec- tion of the taste or talent of the copyist. The best example of this is the set of images of Juncus maritimus in NAP versus $J A C$ (Fig. 8 ) where the $N A P$ copyist has chosen to abstract the foliage in a symmetrical pattern that is reminiscent of Leonardo da Vinci's famous drawing of Ornithogalum (RL 12424).

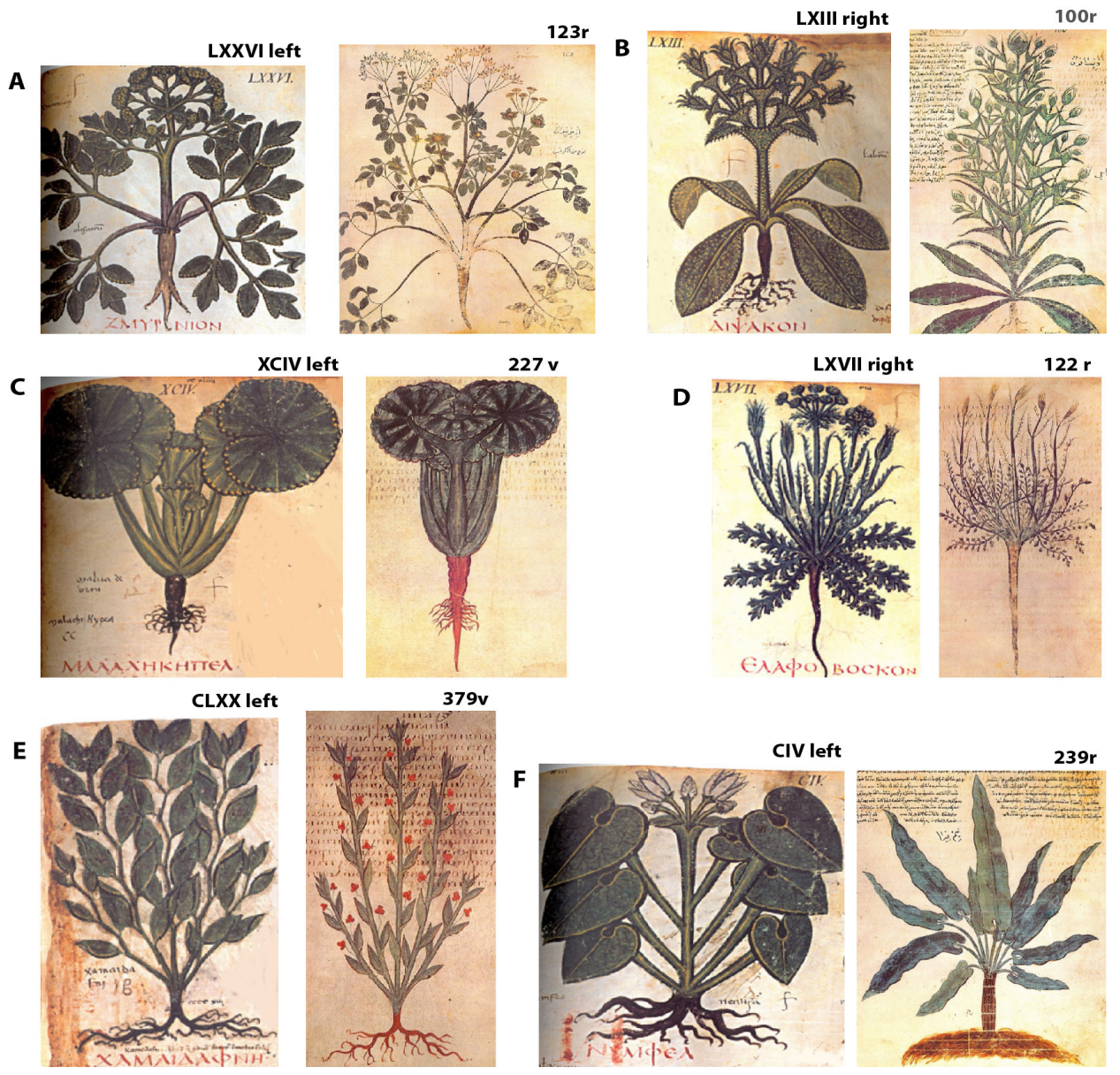

Fig. 7. Stage differences in images of NAP (left) and JAC (right): (A) Bunium pumilum, (B) Dipsacus silvester, (C) Malva silvestris, (D) Pastinaca sativa, (E) Ruscus racemosus, (F) Nymphaea alba
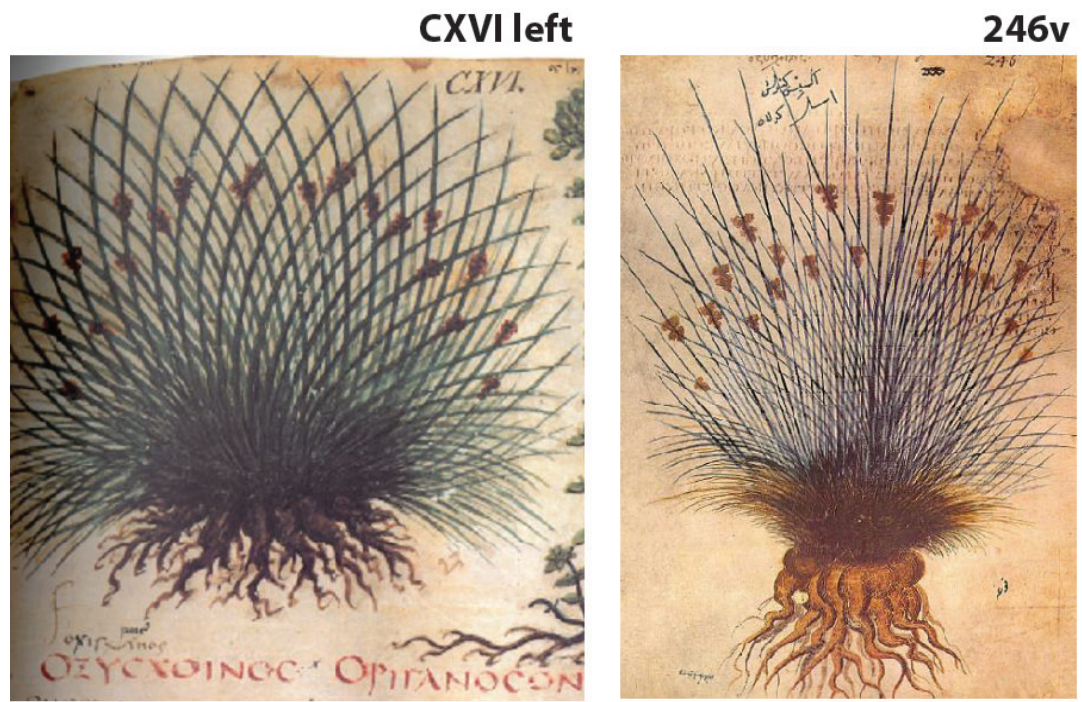

Fig. 8. Artistic differences in images of Juncus maritimus: $N A P$ (left) and $J A C$ (right) 

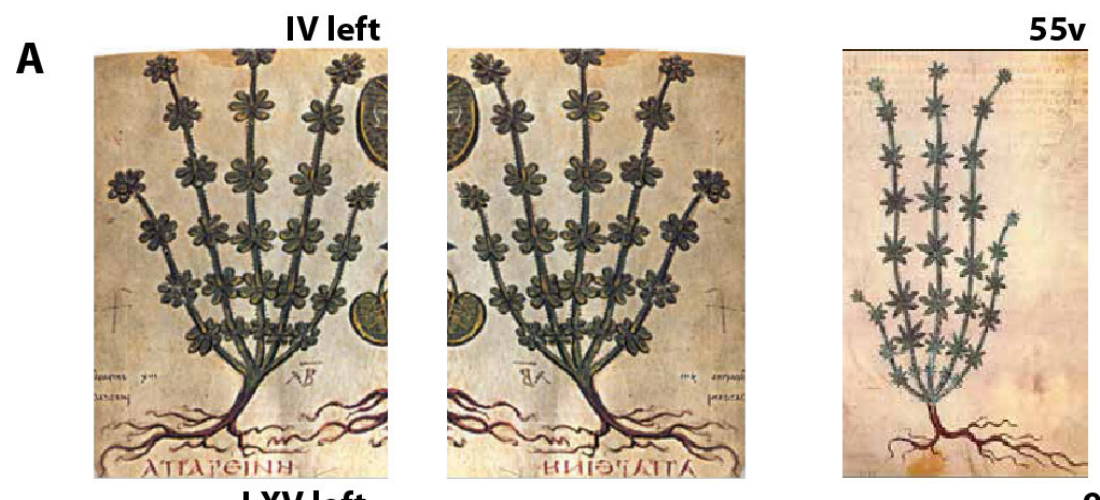

\section{B}



LXXXVIII right

C
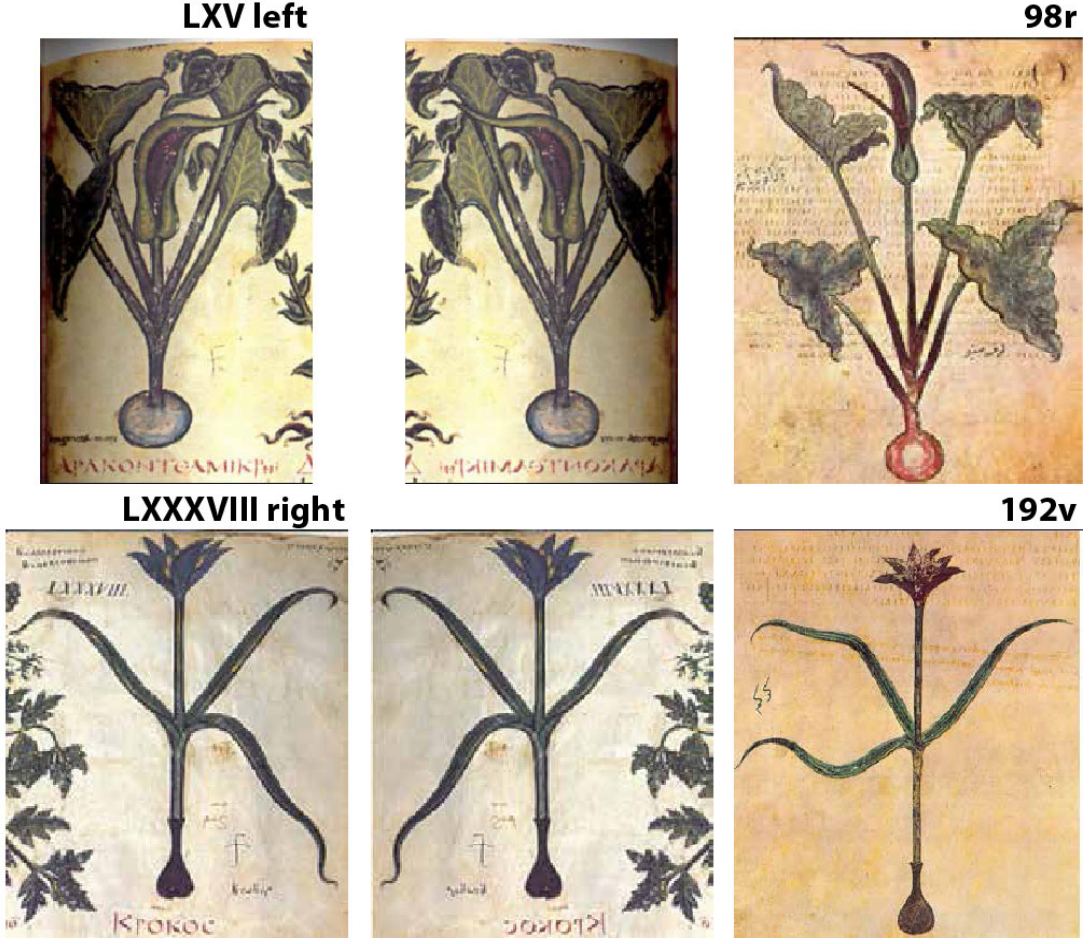

Fig. 9. Mirror images of $N A P$ (center) comparing $N A P$ (left) and $J A C$ (right): (A) Galium aparine, (B) Arum maculatum, (C) Crocus sativum

A number of images in $N A P$ (Fig. 9) appear to be mirror images of the $J A C$ comparison image. It would appear that some copyists may have made tracings of source images to make rough drafts of their drawings. This would account in particular for roots facing in opposite directions.

\section{The Relationship of $N A P$ and $J A C$}

Dioscorides in the preface of his original non-illustrated manuscript makes the point that medicinal plants differ in their properties by a number of factors including stage of growth:

For neither the person who has come across a plant only at the seedling stage can point it out when at its prime, nor can the person who has seen plants in their prime recognize them as seedlings. Because of changes in the leaves, in the size of stems, blossoms, and fruits, and because of certain other characteristics, people who have not make their observations in this manner were greatly mislead regarding some plants.
Similarly, Pliny, contemporary with Dioscorides, but unaware of his work (it is not mentioned in the Historia Naturalis) points out that many writers of plants employed illustrations but is keenly aware that plant illustration is limited by stage:

[Krateuas. Dionysios and Metrodoros] painted likenesses of the plants and then wrote under them their properties. But not only is a picture misleading when the colors are so many, particularly as the aim is to copy nature, but besides this, much imperfections arises from the manifold hazards in the accuracy of copyists. In addition, it is not enough for each plant to be painted at one period only of its life, since it alters its appearance with the fourfold changes of the year. (Pliny 7, 25.4, Jones, 1951)

Collins (2000) suggested that the origins of the $J A C$ are associated with either a lost manuscript or a collection of images made for the Emperor and scholar Theodosius II (401-450), great-grandfather of Juliana. Collins assumes that the $J A C$ was an elaborate presentation volume 
16

made from the manuscripts owned by the Emperor. The manuscript of Theodosius II (THEO) no longer survives but it probably consisted of text plus more than one image of some plants depicting various stages. It would appear that in most cases only one image per plant was chosen as a model for the $J A C$ version. The assumption for multiple images of each plant in THEO can be inferred from the fact that there are multiple images for some plants in $J A C$. The best example may be two images identified by Rina Kamenetsky as two phases, nonflowering and flowering of Pancratium which are presented side by side in NAP (Fig. 10) There are also several pages in $J A C$ where two plants, usually variants of the same species, share a page. For example, Fig. 11 shows two types of Mercurialis annua.

There are a number of possibilities that would explain the relationship of $N A P$ to $J A C$. One is that the scribes of the $N A P$ had both the $J A C$ and its precursor at their disposal. The other is that the NAP was based on either $J A C$ or the precursor alone.

The first explanation is that $N A P$ was based solely on $J A C$ and that some of the various copyists involved could have been familiar with the plants to make changes in the drawings based on their own experience, or had expert botanical assistance. This does not appear likely or viable because there are too many changes (over 10\% of images). Furthermore, it is unlikely that copyists in a studio would have been given so much free reign in the manufacture of these volumes. While most images of $N A P$ and $J A C$ are very similar, they also contain a sufficient number of variations to show that in many cases the former is not considered a direct copy of the latter (Orafino, 1992; Collins, 2000).

The more likely explanation is that there was a trove of previous illustrations to which the copyists of both $J A C$ and $N A P$ had access. Thus, 52 of the 54 unique paintings in $N A P$ must include versions that were never included in the $J A C$. Since $N A P$ contains some plant images that show a different stage of development of the same plant in $J A C$ it is probable that the NAP artists must have obtained them from the same source. Collins (2000) has suggested that the archetypic source of $J A C$ was a collection made for Theodosius II. Our conjecture is that the trove of illustrations in THEO included multiple images of the same plant in some cases, since some of the images in $J A C$ portray images of the same plant at different stages of development. It is likely that the copyists of NAP had both sources available to them, providing a number of plant images from which to choose.

One also has to consider what instructions from the person who commissioned NAP might have specified to the artist-in-charge. If the request was to copy a set of images, one can safely assume the overriding parameter would be "make it faithful to the original." An artist is normally expert at this reproductive task and is unlikely to be an expert botanist; this logic holds as good today as it did in the $6^{\text {th }}$ or $7^{\text {th }}$ century. So it makes eminent sense to us to
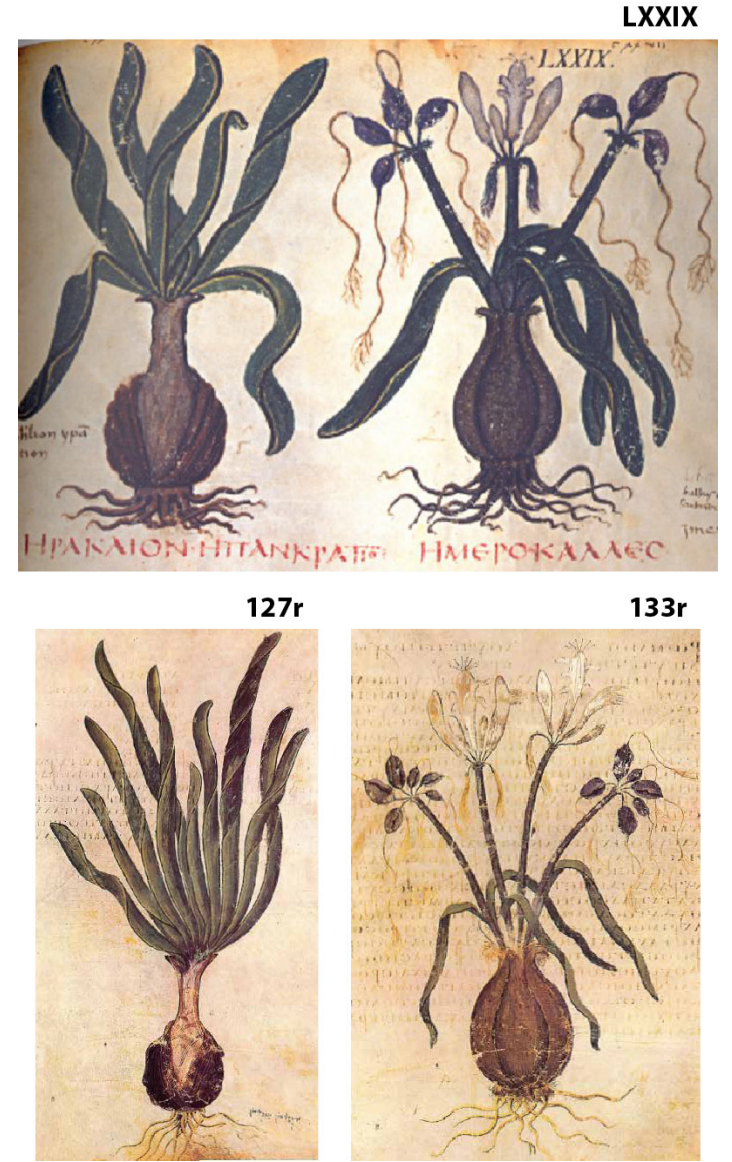

Fig. 10. Phase differences in Pancratium maritimum in $N A P$ (top) and $J A C$ (bottom)
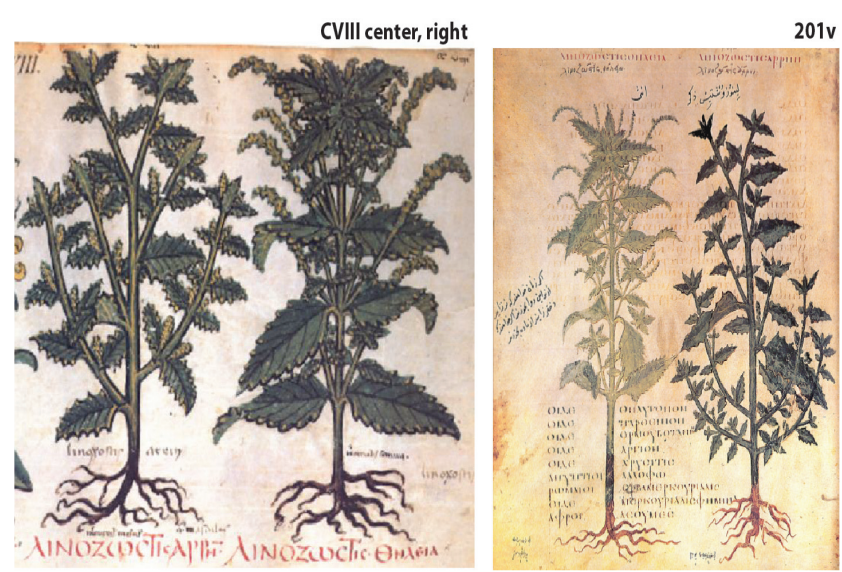

Fig. 11. Multiple images of Mercurialis in NAP (left) and JAC (right)

suggest that the "original/archetype" was a more encyclopedic version and could well have contained, where possible, perhaps two (or more) versions of each plant, depicting the various stages of its development as was discussed and recommended by Pliny. This left the copying artists to select the best example, using aesthetic criteria. We assume that $N A P$ and $J A C$ are most likely to be sister manuscripts from a common source (THEO) but we cannot exclude the possibility that some of the drawings of NAP could 
have been copied directly from $J A C$. Our conclusion is that $N A P$ is an extended version of $J A C$. It probably is a more accurate and comprehensive presentation of the lost manuscript of Theodosius II than $J A C$, because it contains more images.

\section{References}

Beck LY (Ed. trans.) (2005). Pedanius Dioscorides of Anazarbus: De Materia medica. Olms Weidmann, Hildesheim.

Blunt W, Raphael S (1994). The illustrated herbal. $2^{\text {nd }} \mathrm{ed}$. Thames and Hudson Inc, New York, $12-53 \mathrm{p}$.

Cavallo G. (2000). The Naples codex: A codicological description and history of the manuscript, 69-77 p. In: Dioscurides De material Medica, Codex Neapolitanus Graecus I of the

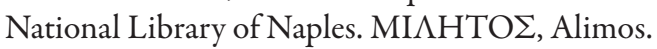

D’Andrea J (1982). Ancient herbs. J. Paul Getty Museum, Malibu, California.

Dioscurides De Materia Medica, Codex Neapolitanus Graecus I of the National Library of Naples. (facsimile). (2000?

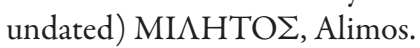

Collins M (2000). Medieval herbals: The illustrative traditions. The British Library, London, 39-105 p.

Der Weiner Dioscorides. (1998-1999). 2 vol. (commentary by Otto Mazal), Akademische Druck-u Verlagsantalt, Graz.

Gunther RT (1959). The Greek herbal of Dioscorides: Illustrated by a Byzantine A.D. 512. Englished by John Goodyer A.D. 1655. Edited and First Printed A.D. 1933. Hafner, New York.

Heyd U (1963). Moses Hamon, chief Jewish physician to Sultan Süleymân the Mangificent. Oriens 16 (Dec. 13):152-170.
Hummer KE, Janick J (2007). Rubus iconography: Antiquity to the Renaissance. Acta Horticulturae 859:89-105.

JanickJ, Hummer KE (2012). The 1500 ${ }^{\text {th }}$ anniversary (512-2012) of the Juliana Anicia Codex: An illustrated Dioscoridean recension. Chronica Horticulturae 52(3) (in press).

Jones WHS (Ed. trans.) (1951). Pliny natural history, Vol VI. Harvard Univ Pres, Cambridge, Massachusetts, 4-11 p.

Mattioli P (1544). Commentarii, in libros sex Pedacii Dioscoridis Anazarbei, de medica materia... Venice.

Orofina G (1992). The Dioscurides of the Biblioteca Nazionale of Naples: The miniatures: In: Commentarium. Dioscurides Neapolitanus: Bibioteca Nazionale de Napoli Codex ex Vindobonensis Graecus 1. Editrice Roma, Salerno.

Renner SS, Scarborough J, Schaefer H, Paris HS, Janick J (2008). Dioscorides's Bryonia melaina is Bryonia alba, not Tamus communis, and an illustration labeled Bruonia melaina in the Codex Vindobonensis is Humulus lupulus not Bryonia dioica, 273-280 p. In: Pitrat M (ed.). Cucurbitaceae 2008, Proc. IX ${ }^{\text {th }}$ EUCARPIA meeting on Genetics and Breeding of Cucurbitaceae. INRA, Avignon.

Scarborough J, Nutton V (1982). The preface of Dioscorides' Materia Medica: Introduction, translation, commentary. Transactions and Studies of the College of Physicians of Philadelphia 4(3):197-227.

Singer C (1927). The herbal in antiquity and its transmission to later ages. Journal of Hellenistic Studies 47:1-52.

Wellman M (1906-1914). Pedanii Dioscuridis Anazarbei De materia medica libri quinque. Three volumes, reprinted 1958. Weidmann, Berlin. 